\title{
Monitoring Hospital Use in the Epidemic
}

\author{
Ronald Lagoe*, Shelly Littau \\ Hospital Executive Council, Syracuse, NY, USA \\ Email: *Hospexcl@cnymail.com
}

How to cite this paper: Lagoe, R. and Littau, S. (2020) Monitoring Hospital Use in the Epidemic. Case Reports in Clinical Medicine, 9, 177-183.

https://doi.org/10.4236/crcm.2020.97025

Received: May 8, 2020

Accepted: June 27, 2020

Published: June 30, 2020

Copyright $\odot 2020$ by author(s) and Scientific Research Publishing Inc. This work is licensed under the Creative Commons Attribution International License (CC BY 4.0).

http://creativecommons.org/licenses/by/4.0/

\begin{abstract}
This study reviewed developments in hospitalization in the metropolitan area of Syracuse, New York during the initial months of the Coronavirus epidemic. The study was based on the use of inpatient discharge data and information contained in daily utilization reports for the three hospitals in the community distributed by the Hospital Executive Council. The data demonstrated that the medical-surgical and critical care inpatient census, as well as the emergency department volume peaked in January 2020 and declined gradually during February and the first half of March as a result of the seasonal influenza season prior to the epidemic. The data showed that with the onset of the epidemic in mid-March, the data identified substantial reductions in the use of inpatient beds and the emergency departments. The medical-surgical and critical care censuses declined by 31.2 and 29.3 percent respectively. This resulted from provider and public efforts to free inpatient beds for coronavirus patients. During April and May 2020, the use of medical-surgical beds and emergency departments in the Syracuse hospital gradually increased as the Coronavirus epidemic plateaued. Subsequent data will identify whether the use of inpatient medical - surgical beds and emergency department visits in the Syracuse hospitals return to the levels before the epidemic.
\end{abstract}

\section{Keywords}

Hospitalization, Epidemic, Influenza

\section{Introduction}

The recent appearance of the Coronavirus and its impact has caused concern in many areas of the world. The impact of the virus has challenged health care systems and governments. It has also challenged health planners at the community level [1].

The impact of the Coronavirus epidemic on providers has been enormous. Hospital utilization has increased in some areas because of the impact of virus 
patients. In many communities, however, it has declined because of the cancellation of scheduled surgery [2]. The epidemic has placed extensive pressure on payers as well as providers [3] [4] [5].

The need to address treatment of virus patients, as well as testing and other functions, has reduced the revenue of many hospitals and other health care providers. This has resulted in furloughing workers and reducing salaries for others [2] [6] [7].

The collection of information concerning the impact of the virus has become a major priority for health planners at the national and local levels. Addressing the virus has required data concerning its incidence and the capacity of health care resources to address it [8] [9].

In this situation, the need for local data has become extremely important. They include information concerning the progress of the disease and the availability of health care resources that are needed to address it. National and statewide information may be interesting, however, local data are required to address the impact of the virus at the community level, where health care is delivered [8] [10].

\section{Population}

This study focused on issues related to the Coronavirus in the metropolitan area of Syracuse, New York. This area includes three acute care facilities, Crouse Hospital-18,863 inpatient discharges excluding well newborns, 2019; St. Joseph's Hospital Health Center-25,250 inpatient discharges, 2019; and Upstate University Hospital-34,217 inpatient discharges, 2019. Between 2016 and 2019, the combined Syracuse hospitals generated an annual average of 225,586 emergency department visits and 63,690 ambulance transports.

These hospitals provide a full range of acute care to an immediate service area with a population of approximately 600,000 . They also provide tertiary acute care services to the Central New York Health Service Area with a population of approximately $1,400,000$.

Historically, the Syracuse hospitals have worked cooperatively to improve the efficiency and outcomes of health care in the community. These efforts have addressed length of stay reduction, emergency department utilization, and other issues through the Hospital Executive Council [11].

\section{Method}

This study described efforts of the Syracuse hospitals to plan for the incidence of the Coronavirus in the early stages of that process. It focused on the use of inpatient discharge data and daily hospital reports to evaluate efforts to address the disease.

The first component of the study identified numbers of adult medicine and adult surgery discharges in the combined Syracuse hospitals for March 16 - April 30, 2020 compared with the same periods in 2018 and 2019. This was the most 
recent time period of the Coronavirus epidemic for which complete abstracted data were available for 2020. Using these data, it was possible to identify the impact of the epidemic on adult medicine and adult surgery discharges for March 16 - April 30.

The discharge data also identified the severity of illness of hospital inpatients according to the $3 \mathrm{M}^{\mathrm{m}}$ All Patients Refined Diagnosis Related Group System. Through comparison of these data for 2018, 2019, and 2020, it was possible to estimate the changes in numbers of discharges in the combined Syracuse hospitals related to the epidemic.

In order to address efforts to contain the Coronavirus, the Hospital Executive Council developed daily reports including indicators related to the utilization of services in the combined hospitals. These indicators included the adult medical-surgical bed census, the adult critical care bed census, the number of emergency department visits, and numbers of ambulances dispatched.

In the second component of the study, the inpatient census and emergency department data were employed to track the utilization of inpatient hospital beds in the Syracuse hospitals. This information was based on data for December 2019 - May 31. It included December 1, 2019 - March 15, 2020, the period before the outbreak; March 16 - April 30, the initial weeks of the epidemic; and May 1-31, the beginning of the recovery from the epidemic.

\section{Results}

Data concerning numbers of inpatient discharges in the combined Syracuse hospitals for March 16 - April 30, 2020 the initial period of the epidemic, are summarized in Table 1.

This information demonstrated that numbers of adult medicine discharges in the hospitals declined by 28.6 percent, from 4681 to 3343, between March 16 April 30, 2018 and 2020. Most of this reduction was generated by low severity of illness patients. It also included patients with Major severity of illness. It was produced by a decline in utilization of hospital emergency departments.

The study data also demonstrated that numbers of adult surgery discharges in the hospitals declined by 46.1 percent, from 2,745 to 1,480, between March 16 April 30, 2018 and 2020. Almost all of this reduction was produced by low severity of illness patients. This reduction was generated by hospital cancellation of elective surgery procedures.

Additional information concerning the impact of the Coronavirus in Syracuse has included daily information concerning inpatient medical-surgical, critical care, and emergency department utilization. Examples of this information for December 2019 - May 2020 are summarized in Table 2.

These data included utilization indicators monitored by the Hospital Executive Council and the Syracuse hospitals. Indicators for the combined hospitals were identified to summarize the use of services at the community level from December 2019 through May 2020. 
Table 1. Inpatient Adult Medicine and Adult Surgery Hospital Discharges by Severity of Illness, Syracuse Hospitals, March 16 - April 30, 2018-2020.

\begin{tabular}{ccccc}
\hline & $\mathbf{2 0 1 8}$ & $\mathbf{2 0 1 9}$ & $\mathbf{2 0 2 0}$ & Difference 2018-2020 \\
\hline Adult Medicine & & & & -385 \\
Minor & 674 & 658 & 289 & -782 \\
Moderate & 1845 & 1669 & 1063 & -365 \\
Major & 1652 & 1792 & 1287 & 194 \\
Extreme & 510 & 721 & 704 & -1338 \\
Total & 4681 & 4840 & 3343 & \\
Adult Surgery & & & & -629 \\
Minor & 931 & 836 & 302 & -585 \\
Moderate & 1119 & 1088 & 534 & -94 \\
Major & 480 & 510 & 386 & 43 \\
Extreme & 215 & 223 & 258 & -1265 \\
Total & 2745 & 2657 & 1480 & \\
\hline
\end{tabular}

Adult medicine data exclude Diagnosis Related Groups concerning surgery, obstetrics, psychiatry, alcohol/substance abuse treatment, rehabilitation, and all patients aged 0 - 17 years. Adult surgery data exclude Diagnosis Related Groups concerning medicine, obstetrics, psychiatry, alcohol/substance abuse treatment, and all patients aged 0 - 17 years. Source: Hospital Executive Council.

Table 2. Hospital Utilization Data, Medical - Surgical, ICU/CCU, Ambulances Dispatched, Emergency Department Visits, Syracuse Hospitals, December 2019 - May 31, 2020.

\begin{tabular}{ccccc}
\hline & $\begin{array}{c}\text { Adult Medical - } \\
\text { Surgical Census }\end{array}$ & $\begin{array}{c}\text { Adult ICU/CCU } \\
\text { Census }\end{array}$ & $\begin{array}{c}\text { Ambulances } \\
\text { Dispatched }\end{array}$ & $\begin{array}{c}\text { Emergency } \\
\text { Department Visits }\end{array}$ \\
\hline December 1, 2019 & 612 & 117 & 170 & 534 \\
January 1, 2020 & 679 & 131 & 173 & 620 \\
February 1, 2020 & 615 & 124 & 171 & 646 \\
March 1, 2020 & 606 & 114 & 169 & 569 \\
March 16, 2020 & 626 & 116 & 169 & 630 \\
March 31, 2020 & 419 & 86 & 103 & 318 \\
April 1, 2020 & 431 & 82 & 127 & 306 \\
April 15, 2020 & 439 & 89 & 127 & 336 \\
April 30, 2020 & 470 & 114 & 123 & 389 \\
May 1, 2020 & 477 & 100 & 126 & 401 \\
May 15, 2020 & 533 & 103 & 154 & 450 \\
May 31, 2020 & 617 & 125 & 133 & 419 \\
\hline
\end{tabular}

Source: Hospital Executive Council.

The data indicate that the inpatient medical-surgical census excluding critical care beds in the Syracuse hospitals declined by 10.8 percent, from 679 to 606 , between January 1, 2020, when the census peaked during the seasonal influenza season, and March 1, 2020. During the same period, the critical care bed census 
declined by 13.0 percent, from 131 to 114 . These reductions appear to have been generated by inpatient utilization related to the seasonal influenza season. Historically, seasonal influenza has increased in January and declined during the following months in the Syracuse hospitals.

The study data also identified a decline in the inpatient medical-surgical census in the Syracuse hospitals of 31.2 percent, from 626 to 431 and a decline of 29.3 percent in the critical care bed census, from 116 to 82, between March 16 and April 1, 2020, the initial period of the epidemic. This reduction was generated by hospital efforts to free inpatient medical - surgical beds for patients with the Coronavirus. It resulted in the identification of more than 200 beds for this purpose as demonstrated by the reduction in the medical-surgical census.

These reductions were followed by a 43.2 percent increase in the medical-surgical census of the hospitals, from 431 to 617 , and a 52.4 percent increase in the ICU/CCU census from 82 to 125 during April and May 2020. This increase appears to have been generated by adult medicine and adult surgery patients returning to the hospitals.

The data in Table 2 also identified a reduction in emergency department visits of 8.2 percent, from 620 to 569, for the combined Syracuse hospitals between January 1, 2020 and March 1, 2020. This decline was probably related to the seasonal influenza season.

It was followed by 31.6 percent decline, from 569 to 389, in emergency department visits for the combined hospitals between March 1 and April 30, 2020. This resulted from efforts to avoid over use of the emergency departments for testing for the virus.

During April and May 2020, the number of daily emergency department visits for the combined Syracuse hospitals increased by 36.9 percent, from 306 to 419 . This contributed to an increase of 43.2 percent in the medical-surgical census, from 431 to 617. Emergency department visits increased at a lower rate than the medical - surgical census. This increase included the return of adult medicine and adult surgery patients to the hospitals.

During the period between January 1 and April 30, 2020, the changes in the combined medical-surgical census were closely related to emergency department volumes. This relationship was confirmed by a 0.9345 Pearson Correlation between January 1 and April 30, 2020 and a Pearson Correlation of 0.9165 between March 1 and May 31, 2020.

\section{Discussions}

This study reviewed developments in hospitalization in the metropolitan area of Syracuse, New York during the initial months of the Coronavirus epidemic. It focused on the use of major services including inpatient medical-surgical and critical care beds, as well as emergency departments.

The study was based on the use of inpatient discharge data and information contained in daily utilization reports for the three hospitals in the community 
distributed by the Hospital Executive Council. Using this information, it was possible to track substantial changes in the utilization of hospital services.

The data demonstrated that the medical-surgical and critical care inpatient census, as well as the emergency department volume peaked in January 2020 and declined gradually during February and the first half of March. These developments resulted from seasonal influenza prior to the epidemic.

With the onset of the epidemic in mid-March, the data identified substantial reductions in the use of inpatient beds and the emergency departments. The medical-surgical and critical care censuses declined by 31.2 and 29.3 percent respectively. This resulted from provider and public efforts to free inpatient beds for Coronavirus patients. These efforts included cancellation of elective surgery and discouraging use of emergency departments.

During April and May 2020, the use of medical-surgical beds and emergency departments in the Syracuse hospitals gradually increased as the Coronavirus epidemic plateaued. This was paralleled by greater use of adult medicine inpatient beds and the hospital emergency departments.

The study data demonstrated that the increased use of medical-surgical beds during April and May 2020 offset the previous reduction during the onset of the epidemic. The current data do not demonstrate whether the increase in emergency department utilization will offset all of the previous reduction.

The differences between the changes in these utilization indicators were important. They suggest that, at least for emergency department utilization, the impact of the epidemic could be permanent.

\section{Conflicts of Interest}

The authors declare no conflicts of interest regarding the publication of this paper.

\section{References}

[1] Kacik, A. (2020) We Have to Be Ready. And We Are Not. Modern Healthcare, 50, 12-14.

[2] Livingston, S. (2020) Providers Sideline Employees, Cut Pay as Pandemic Saps Revenue. Modern Healthcare, 50, 6-7.

[3] Bannow, T. and Brady, M. (2020) COVID-19 Could Accelerate Medicare's March toward Insolvency. Modern Health Care, 50, 6.

[4] Johnson, S.R. (2020) How Ability and Years of Planning Help Three System Battle COVID-19. Modern Healthcare, 50, 10. https://doi.org/10.18683/germs.2020.1192

[5] Cohrs, R. (2020) HHS Issuing \$40B in Cares Act Checks But Some Providers May Still Miss Out. Modern Healthcare, 50, 8.

[6] Brady, M. (2020) Rolling Back Relief Will Be Tricky for HHS, Industry. Modern Healthcare, 50, 8-9.

[7] Bannow, T. (2020) AHA, ACS and Others Release Guidelines for Resuming Elective Surgeries. Modern Healthcare, 50, 8.

[8] Goozner, M. (2020) Big Data's Role in Addressing COVID-19. Modern Healthcare, 
$50,22$.

[9] Castellusi, M. (2020) Girding for the Surge: How One System Got Ready for Expected COVID-19 Influx. Modern Healthcare, 50, 10-11.

[10] Mulder, J. (2020) As Coronavirus Patients Cram NYC Hospitals, Syracuse Hospitals Still Have 300 Empty Beds. Syracuse.com, March 30, 2020.

[11] Lagoe, R. and Littau, S. (2020) Hospital Utilization and the Respiratory Disease Season. Case Reports in Clinical Medicine, 9, 40-46.

https://doi.org/10.4236/crcm.2020.91007 